\title{
Challenger and Defenders of the America's Cup
}

\author{
Leading Characteristics of "Shamrock IV," "Resolute" and "Vanitie"
}

\section{By J. Bernard Walker}

B $\mathrm{Y}$ the courtesy of Mr. C. E. Nicholson, designer of B Sir Thomas Lipton's challenging yacht, "Shamrock IV," we are enabled to present the exact outboard profile, midship section, and other leading characteristics of the British craft. Similar data regarding the cup defenders, "Vanitie" and "Resolute" were ing the cup defenders, "Vanitie" and "Resolute" were dreamed that a furious contest between ships of war was to take the place of the proposed friendly struggle between ships of pleasure.

With regard to the diagrams of the three yachts, we invite attention to the curious fact noticeable in a comparison of "Resolute" with "Shamrock IV," that the American and British designers have changed places during the past thirty Volunteer contest, we find that the British cutter was a boat of moderate beam and a deep V-section, with easy bilges, large displacement and moderate sail area, whereas the sloop derived her greater sail-carrying power from her great beam, and hard, full bilges. Comparing the midship section of "Resolute" and "Shamrock IV," it will be seen at a glance that it is now the American boat that has the easy bilges and is full at the garboards, and that it is the English boat that has the greater beam, the hard bilges, the long, fiat dead rise and the sharp turn at the gar. boards; while as regards sail area, the difference is enormous in favor of the British boat, seeing that she has almost exactly a 25 per cent greater sailspread.

"Resolute" comes from the designing board of Nat Herreshoff; the other defender, "Vanitie," was designed by William Gardner, who has always run Herreshoff rather closely for first honors in racing yachts of the rarious classes "Vanitie," which was built in 1914 for Alexander S. Cochrane, has been deeded built in 1914 for Alexander S. Cochrane, has been deeded
by him to the New York Yacht Club, and both "Vanitie" and "Resolute" are now having their competitive trials under the management of that club, with a view to selecting the better boat for meeting "Shamrock IV" in the races of 1920. Referring to our comparison above of "Shamrock IV" and "Reliance," it can be said that "Vanitie" comes midway between these extreme types.

The three yachts were designed in 1914 under the new rule of measurement which was intended to correct the defects of the old rule. Under the old rule, waterline length and sail area only were considered. So long as the yacht did not exceed 90 feet on the

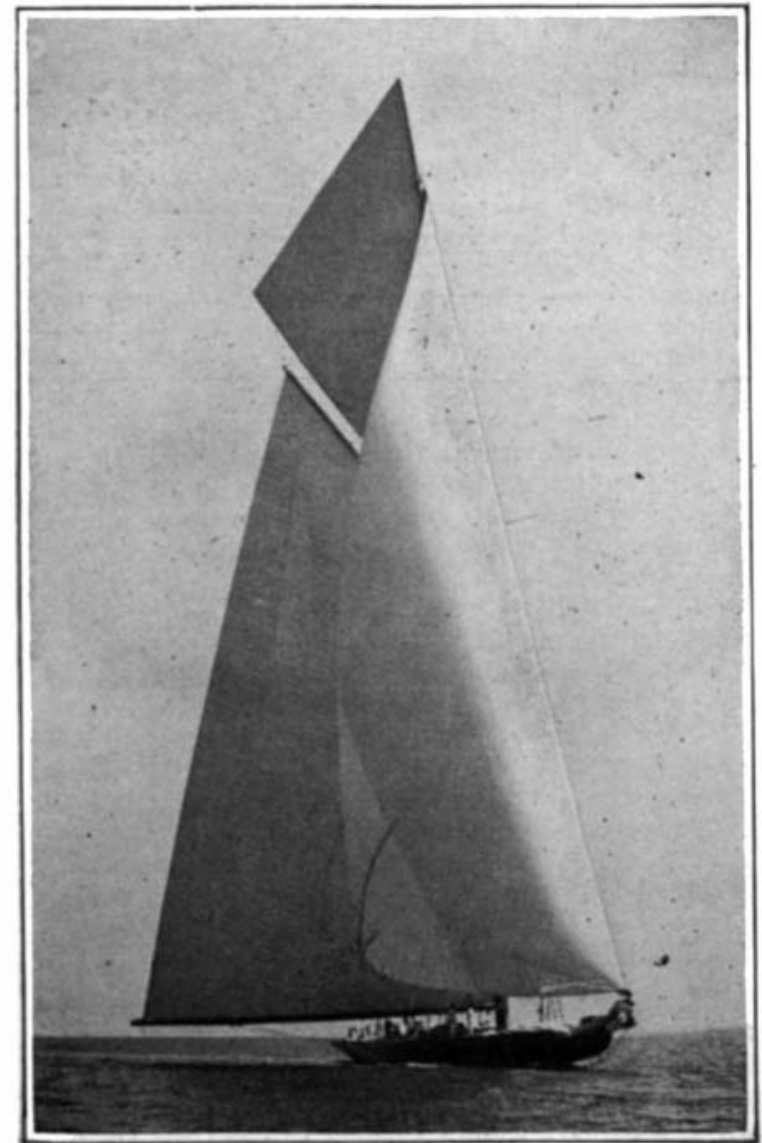

On a broad reach, carrying balloon jib and largest clubtopsail

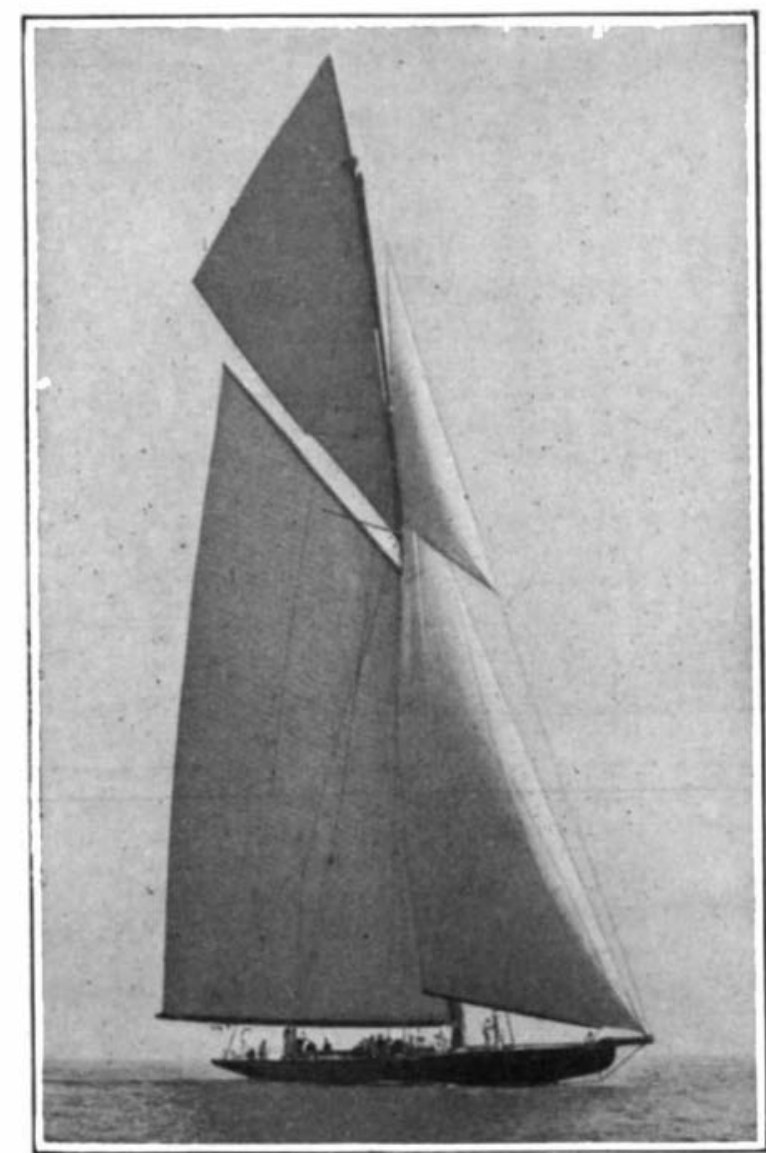

Shamrock IV, whose spread of sail reaches 170 feet above the deck

water line, the designer was free to make her as broad, as deep, and as long on deck as he pleased, and he could give her as large a sail plan as he wished. Working under this rule, it was found that a yacht with a broad, shallow, scow-shaped hull, with long overhangs, carrying a great mass of lead at the bottom of a deep keel, and driven by a vast spread of sail, produced the fastest yacht under the average weather conditions off Sandy Hook. The most extreme yacht built under that rule was "Reliance," which, with 90 feet of waterline length, measured 140 feet on deck and spread over 16,000 square feet of canvas.

Now, the old rule produced "freak" yachts. Their spars were too big, their hulls too shallow and their draft too great, to render them useful as cruisers; the races over, they were generally broken up for junk.

The new rule was drafted with a view to producing a more wholesome boat, with a larger displacement, a smaller draft, and a sweeter form with sharp endsthat is to say, a form which would have a much easier motion in a seaway than the old scow form, whose full, flat bows pounded heavily and made the boats extremely wet when thrashing to windward in a short sea.

Now in drafting out a racing yacht of the kind that competes for the America's Cup, the designer may approach the problem from two different angles. He may decide to build as small a boat as he thinks will have sufficient speed, plus its time allowance, to make sure of winning the cup; or he may decide to build the largest and most powerful craft that can be brought within the limits of length, draft and displacement laid down, believing that the higher speed gained from size and power will more than ofiset the time allowance which he must give to the smaller craft. What makes the contest this year so interesting is that whereas, let us say, Herreshoff has built a boat of moderate form and power, Nicholson has gone to the very limit in the other direction and turned out a boat in which he has bid for power in every direction in which it could be secured. If "Vanitie" should be chosen to defend the cup, "Shamrock IV" will undoubtedly have to give considerable time allowance to that boat, and should "Resolute" be chosen she will that boat, and should "Resolute" be chosen she will she shall show phenomenal speed on all points of sailing, her task would seem, at the very first sight, at lesst, to be something of a forlorn hope. The hulls of the American boats are built of nickelsteel framing, plated with manganese bronze. The "Resolute" construction consists of a series of 16 web frames, 8 to 12 inches in depth, with lighter frames between, the latter extending from keel to bilge, and longitudinal framing following the seams of the shell plating, which is 5/32-inch manganese bronze. She is decked wlth aluminum plates $7 / 32$ of an inch thick, the whole being covered with canvas, sanded to give a good footing.

"Vanitie's" framing consists of eight 10-inch veb frames, with light intermediate frames extending from the keel to the deck. As originally built in 1914, she had a light pine deck laid on nickel-steel deck beams. In both yachts the masts, 20 inches in diameter, were built of nickel-steel, with angle-iron stiffeners.

A study of the plans which we publish shows that, upon every point of comparison, the hulls of the challenger and the defenders are as wide apart, both in design and construction, as they can well be. Herreshoff, seeking to take every possible advantage of the new rule and secure as small a rating as possible, has built a small boat of moderate power; whereas Nicholson has been willing to incur heavy penalties in order to secure a boat of great initial stability, capable of carrying a huge spread of canvas. The result is shown in the fact that, though the boats are of practically the same displacement, 1051/2 tons for "Resolute" and 106 tons for "Shamrock IV," the latter carries 25 per cent more canvas, or 10,800 square leet as agninst 8,650 square feet for "Resolute."

The explanation of this anomaly is to be found in the form of the hulls, the character of their construction, and the placing of the lead ballast; and it is in the daring with which he has handled these problems that designer Nicholson has produced a challenger, which, for startling originality, may well make the yachting sharp gasp at the first sight of her.

In the matter of form, or madel, he has adopted the champagne-glass midship section, which characterized "Reliance" and "Independence," with full, hard bilges which, in defiance of the quarter-beam penalty imposed by the new rule, he has carried out well into the bow and stern sections.

In the matter of ballast he has lengthened his lead to $321 \%$ feet and bulbed it out to a width of $31 /$ feet with the result that its center of gravity is only about

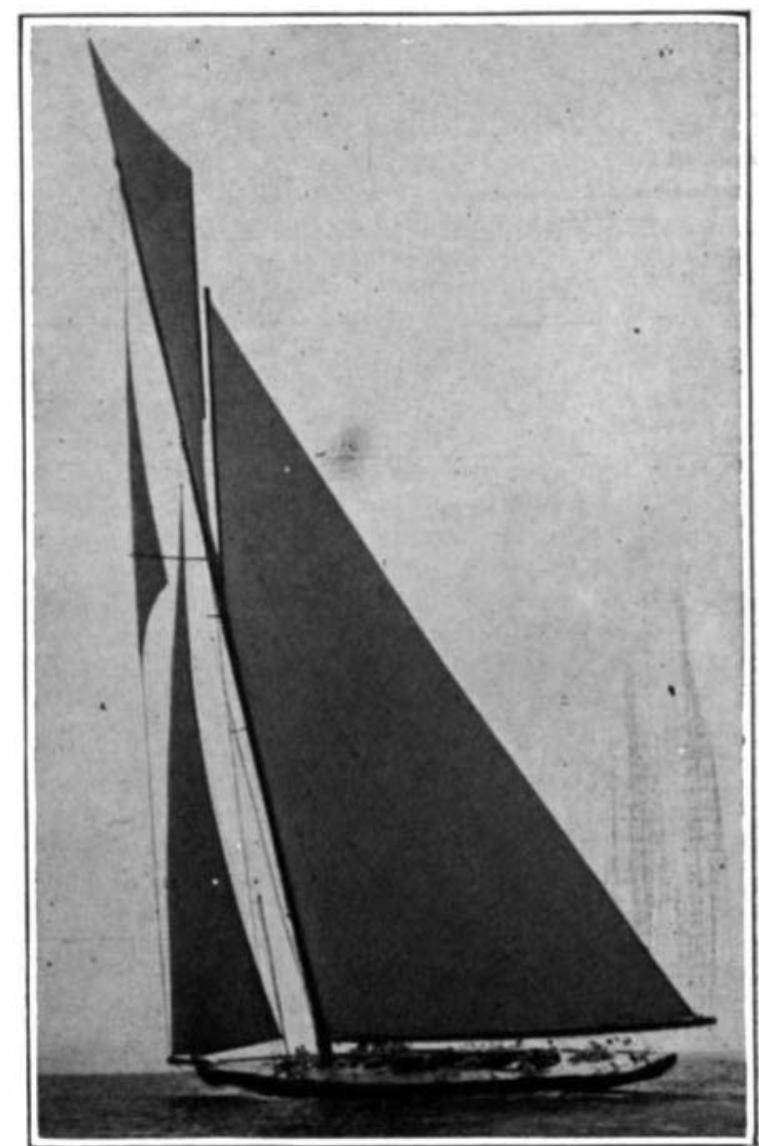

Close hauled on starboard tack. Note the perfectig fitting canvas 
16 inches above the bottom the keel. The lead on "Resolute" being only 20 feet long, necessarily extends much higher, and its center of gravity, since it is not flared out at the base, is about 30 inches above the hase of the keel-a difference in the righting moment of the lead which means more sail-carrying capacity for the same weight. This long, low lead means very large lateral plane-good for windward work but bad for progress in light airs, when the large wetted surface involved will prove a handicap.

But it is in the construction of the hull that the greatest departure has been made. The framing consists as in the American boats of deep web frames, widely spaced, with light angle-iron frames between them, but this framing is of such lightness that, when one thinks of the towering rig aloft reaching 170 feet one thinks of the towering rig aloft reaching 170 feet puzzling how the hull can carry the heavy stresses to puzzling how the hull can carry the heavy stresses to
which it is subjected. But if you ask designer Nicholwhich it is subjected. But if you ask designer Nichol-
son he will tell you of the wonderful strength of carefully selected, well-seasoned and properly disposed wood. He will explain that the hull is sheathed with three layers of mahogany, two layers, $1 / 2$ inch thick, placed diagonally in opposite directions at 40 degrees to the vertical, and an outer laver $5 \%$ inch thick, placed longitudinally, the whole being very thoroughly fastlongitudinally, the whole being very thoroughly
ened together, with the joints evenly distributed. Although "Shamrock" is ne a rly seven years old and was sailed hard across the Atlantic, and has never been caulked, she is tight as a drum today. In the designer's eyes, the value of this construction lies in its continuity. It is practically without joint or seam, and to great strength and toughness it adds what merit there may be in its
elasticity. The deck is of birch veneer, $5 / \%$ of an inch in thickness, and the hull is stiffened against distortion by running birch veneer bulkheads at each web frame from web frame from deck along each deck along each side of the hull. The hull is also stiffened longitudiof wood longitudinals, about 21/2 inches square in section. The fact that "Shamrock" and a much heavier rig on a larger hull, for the same displacement, shows how extremely light the construction of the hull must be.

Another striking novelty (for a cup yacht) is the the topsides, which will assist the boat long, easy sailing lines, when she is rail down in a stiff breeze. She will not tend to "roll out," as a boat with flaring topsides is apt to do, and with her huge sailspread she should, like "Independence," gather speed quickly when sheets are eased on a reach.

The great height of the rig, coupled with the tumble The great height of the rig, coupled with the tumble
home, necessitated the use of outrigger chainplateshome, necessitated the use of outrigger chainplates-
another return to abandoned practice. The mast, feet in diameter, is of wood and hollow, as are the other spars. The topmast truck is $\mathbf{1 4 5}$ feet and the top of the clubtopsail 170 feet above the deck. This means that if the "Shamrock" were afloat on Broadway, the topmost point of her clubtopsail would be level with the cornice of a 14-story building-and this, remember, on a waterline of 75 feet.

All the yachts have made changes over 1914 in preparation for the 1920 races. "Shamrock" has the same rig, but she has lightened herself by cutting off 8 ton of lead from the ends of her keel and bolting a 5-ton pad along the bottom. To bring her down to the 75foot length a mahogany pad several inches in thickness has been worked on to her stem.

The changes in "Vanitie" and "Resolute" have been in the direction of larger sail area; and the former has paid the visitor the compliment of adopting the eneer deck, while "Resolute" has followed suit by changing from a steel to a hollow wooden mast.

\begin{tabular}{|c|c|c|}
\hline W. L Shamrock IV & Vanitie & $\underset{75^{\prime}}{\text { Resolute }}$ \\
\hline Draft $\ldots \ldots \ldots \ldots \ldots 1^{\prime} 9^{\prime \prime}$ & $13^{\prime} 9^{\prime \prime}$ & $13^{\prime} 9^{\prime \prime}$ \\
\hline Beam $\quad \ldots \ldots \ldots \ldots 22^{\prime} 4^{\prime \prime}$ & $22^{\prime}$ & $21^{\prime}$ \\
\hline Overhang forward.17'6" & $2 \cdot 2^{\prime} 6^{\prime \prime}$ & $16^{\prime}$ \\
\hline Overhang aft $\ldots .18^{\prime}$ & $21^{\prime}$ & $15^{\prime}$ \\
\hline Length over all...110'6" & $118^{\prime} 6^{\prime \prime}$ & $106^{\prime}$ \\
\hline Fore triangle base $.55^{\prime}$ & $55^{\prime} 5^{\prime \prime}$ & $48^{\prime} 4^{\prime \prime}$ \\
\hline Boom.$\ldots \ldots \ldots .66^{\prime}$ & $79^{\prime} 5^{\prime \prime}$ & $78^{\prime}$ \\
\hline Deck to topmast.. $148^{\prime}$ & $13 \bar{\Xi}^{\prime}$ & $130^{\prime}$ \\
\hline Lead, tons . .....67 & 65 & 65 \\
\hline Displacement, tons.106 & $10 \bar{\tau}$ & $1051 / 2$ \\
\hline Sail area $\ldots \ldots \ldots 10,800^{\prime}$ & $9,600^{\prime}$ & $8,650^{\prime}$ \\
\hline
\end{tabular}

There has been much comment about the appearance of a slight "hogging" in the deckline of "Shamrock." The freeboard is $6^{\prime} 2^{\prime \prime}$ at the stem. The deck runs straight to a point above the forward end of the waterline where the freeboard is still $6^{\prime} 2^{\prime \prime}$-this to prevent water from coming aboard and keep the chainplate outriggers clear of the water. From this point

also their influence on the fertility of soils and their work in expediting rock decay are still subjects of scientific study. Bacteria evidently not only aid in the decomposition of rocks and in the formation of beds of chalk and inmestone, as has recently been demonengineers have learned that irondepositing bacteria may be troublesome pests through their ability to clog the pipes of city water-supply systems with hard, thick crusts and slimy, rusty masse composed of millions of individuals. Mr. E. C. Harder, of the United States Geological Survey, who has examined deposits of iron ore in many countries for the special purposes of determining their mode of origin has recently made close studies of the action of bacteria in forming iron ores. called "iron bacteria" actively engaged in the deposition of compounds of iron, not only in the surface irontion of compounds of iron, not only in the surface iron-
bearing waters, but in mine waters to depths of sevcral hundred feet, and has made laboratory cultures of various iron-depositing bacteria.

\section{X-Ray Paper}

R. G. W. K. CROSLAND and Mr. T. P. K. Crosland, Ruddersfield, are the inventors of a novel and ingenious device relating to $\mathrm{X}$-ray photographs and radiograms, which has for its object the provision of sensitized flexible material or paper so prepared as to admit of one, two or more copies being directly obtained with one exposure and avoid ing the loss of time occupied in making an exposure on glass and then printing from same, such flexible sensiing advantageous in that it is easily adapted to any part or angle or curve being radiographed, while there is no risk of breakage. The inventors take a like flexible material previously sensitized in any known manner and treat or coat the same with a paint or wash of vene tian red, chrome yellow or other suitable preparation which is impervious to light and is easily removable by wash-

the deck falls to a freeboard of $4^{\prime} 7$ "at the after end of the waterline. Then it rises one inch to $4^{\prime} 8^{\prime \prime}$ at the stern.

As to the coming races, "Shamrock" is certainly a dark horse, and until the starting gun is fired off Sandy Hook, no one, not even the designers themselves, can guess whether challenger or defender will open out a lead. We know that "Resolute" and "Vanitie" have sailed a 30 -mile course faster than it has ever been sailed in these waters; we know also that "Sham rock IV" has beaten "Shamrock III" (the fastest 75foot yacht in British waters) a minute and a quarter a mile on a 15-mile beat to windward. The result would seem to turn on the question whether she can save the five, six or seven minutes of time allowance which she will have to allow the American boat.

\section{A New Kind of Bacteria}

$\mathbf{R}$ ECENT investigations are showing more and more $R$ the extent to which ther field than disease.

Geologists are realizing more fully as they extend their studies the magnitude of the work done by plants and animals in building up and tearing down parts of the crust of the earth. Even microscopic organisms perform a large part of this work. Pasteur long ago showed not only the deadly power of bacteria in disease and their efficiency in promoting fermentation, but ing or other simiing or other simi-

"Resolute"

said opaque coating or covering forms an adequate protection to the sensitized surface and admits of the laper or material thus treated being handled or car
ried openly, and dispensing with the use of light-tight envelopes, cassettes and the like, the treated pape being made up in single sheets or arranged in books, packets or blocks containing the desired number of sheets.

For producing a print or prints, the prepared sheet or material or two or more superimposed sheets or papers is supported behind the object to be radio graphed and may be placed in any angle to best suit the object, or in any curved surface to bring the whole of the surface as near to the object as is possible to give the best results, the print being thus taken directly on the paper or sheet or a like print on each of the superimposed papers or sheets which are subsequently washed or treated to remove the opaque surface by coating and develop the print or prints.

By means of this invention, X-ray photographs or radiograms can be produced with the utmost rapidity whereby immediate inspection of the finished print is obtainable, this in many cases being of considerable value. The cost of manufacture of the sensitized paper being less than that of sensitized glass and the subsequent developing operation being minimized, the production of radiograms is cheapened.-By $A . H . J$. Keane. 